In general, strategies for the treatment of cancer in pregnancy should not differ significantly from the treatment regimens in non-pregnant women. However, this is difficult due to either the effects of anticancer drugs on the developing foetus or the possibility of long-term complications after the exposure to drugs and radiation.

The decision about the introduction and continuation of treatment in the event of pregnancy should be preceded by a detailed analysis of the potential benefits and risks. There are no data to suggest that pregnancy termination alters the biological behaviour of the tumour or patient prognosis in the presence of appropriate antineoplastic therapy. All patients should be given appropriate advice and informed that there are insufficient scientific data to determine any generally accepted consensus. It is very important to always respect the will of the patient, and the moral judgment of the physician should have no impact on the decisions taken by the woman. If the woman decides to undergo active treatment and maintain her pregnancy, it is necessary to carry out consultations with experts in the field appropriate to the type of cancer. This paper presents a basic review of the literature on the targeted therapies currently used in selected cancers diagnosed during pregnancy: breast cancer, cervical cancer, Hodgkin's disease, melanoma, thyroid cancer, ovarian cancer, and colorectal cancer.

Key words: cancer pregnant, preg nancy-associated breast cancer, melanoma, lymphoma, thyroid, ovarian, colorectal cancer.

Contemp Oncol (Pozn) 2015; 19 (5): 354-360 DOI: $10.5114 /$ wo. 2014.46236

\section{Cancer treatment in pregnant women}

\author{
Pawel Basta ${ }^{1,2}$, Anna Bak ${ }^{3}$, Krzysztof Roszkowski
}

${ }^{1}$ Department of Surgery, Jagiellonian University, Medical College, Krakow, Poland ${ }^{2}$ Department of Gynaecology and Oncology, Lukaszczyk Oncology Centre, Bydgoszcz, Poland

3Department of Radiotherapy, Lukaszczyk Oncology Centre, Bydgoszcz, Poland

\section{Introduction}

Malignancies in pregnant women account for $0.05-0.1 \%$ of all cancers. They are associated with $0.02-0.1 \%$ of all pregnancies; one in 1000-1500 pregnancies is complicated by the presence of cancer in the mother [1, 2]. There is some controversy about the effects of pregnancy on the progression and prognosis of cancer. Current knowledge is based on the results of phase II studies, retrospective analyses, and systematic reviews of the literature. For this reason, clinically relevant decisions are often made without knowledge of reliable scientific data.

In general, strategies for the treatment of cancer in pregnancy should not differ significantly from the treatment regimens in non-pregnant women. However, this is difficult due to either the effects of anticancer drugs on the developing foetus or the possibility of long-term complications after the exposure to drugs and radiation.

Following a diagnosis of cancer in pregnancy, the decision about how to proceed should be made jointly by a multidisciplinary team consisting of a surgeon, a clinical oncologist, a specialist in radiation therapy in oncological gynaecology, an obstetrician, and a psychologist, with active involvement and support from the family of the pregnant patient. This paper presents a basic review of the literature on the targeted therapies currently used in selected cancers diagnosed during pregnancy: breast cancer, cervical cancer, Hodgkin's disease, melanoma, and thyroid cancer.

\section{Therapeutic options in pregnant patients with cancer}

\section{Surgery}

Surgery is the mainstay of treatment of solid tumours, and pregnancy is not a contraindication to a surgery. Thanks to the use of modern surgical techniques and anaesthesia, maternal mortality is negligible. Operation in the first trimester does not appear to increase major birth defects, but the risk of miscarriage increases. Therefore, when possible, surgery should be deferred until the second trimester, when the risk to the foetus is lowest.

Surgical treatment of non-neoplastic conditions in pregnant women includes cases of cholecystitis, appendicitis, and ovarian cysts. Anaesthesia during pregnancy is considered to be safe [3] and most anaesthetics are safe for the foetus [4]. Negative effects for the foetus are more correlated with maternal hypoxia, hypotension, hypothermia, or abnormal glucose metabolism than with anaesthesia. The risk of pregnancy loss and congenital defects does not increase because of surgery. Preterm births usually occur in cases of abdominal surgeries and peritonitis [5, 6]. Since pain can also induce premature labour, it is important to administer appropriate postoperative analgesia. Moreover, prophylaxis of thrombosis should also be implemented [7]. A surgery in the first trimester slightly increases the risk of foetal loss due to general anaesthesia [8]. Laparoscopic surgery can be carried out during pregnancy by an experienced physician [5, 6]. 


\section{Chemotherapy}

Most of the damage to the foetus has been reported during embryogenesis and organogenesis (up to the $60^{\text {th }}$ gestation day), which justifies dispensing with any chemotherapy $(\mathrm{CTH})$ in the first trimester of pregnancy. After the administration of cytotoxic chemotherapy during pregnancy, especially during the first trimester, the occurrence of birth defects is about $20 \%, 40 \%$ of which regard low birth weight, and about $33 \%$ of which regard pancytopenia [9]. The most adverse antimetabolites are aminopterin, methotrexate, and cytosine arabinoside, and in the group of alkylating agents - chlorambucil, mechlorethamine, and cyclophosphamide. In the literature there is no information on the threat posed to the foetus by plant alkaloids and anthracyclines because they are composed of large molecules, which probably have more difficulty in passing through the placenta. Platinum derivatives cause some delay in the development of the foetus and may cause hearing deficiency. Etoposide can cause pancytopenia in foetuses and newborns, and a higher risk of secondary leukaemia. A number of reports on the use of toxoids (docetaxel and paclitaxel) in pregnancy indicate no harm to the foetus in the second and third trimester of pregnancy in pregnant women treated for breast cancer and ovarian cancer. If the use of chemotherapeutics during pregnancy is necessary, the least harmful platinum preparation is cisplatin (carboplatin is more toxic to the bones), while among anthracyclines, doxorubicin is recommended. The use of epirubicin and liposomal forms of anthracyclines is more dangerous because of the higher degree to which these drugs overcome the barrier of the placenta [10].

Most cytotoxic drugs have a relatively low molecular weight and can cross the placenta. Because of its teratogenic and mutagenic effect, chemotherapy is contraindicated during the first trimester of pregnancy. However, in some cases, chemotherapy is used after the period of organogenesis. Breast-feeding by pregnant women undergoing CTH is contraindicated because the drugs are excreted with breast milk [10]. Tamoxifen and aromatase inhibitors should be deferred until after the delivery, due to their teratogenic effect observed in animals and humans [11]. Table 1 shows the main risks to the foetus of chemotherapeutic agents.

\section{Radiation therapy}

The adverse effects of radiation were first described at the beginning of the previous century. Cases of birth defects have been reported in children of mothers who received a dose of radiation to the pelvic area during pregnancy. Such children demonstrated microcephaly, mental retardation, stunted growth, microphthalmus, retinal degeneration, cataracts, and defective dentition [12]. In principle, radiation therapy should be avoided during pregnancy, if possible. The neck and mediastinum can be considered as an area for irradiation, provided that the region of the pelvis is excluded.

The biological effect of irradiation depends on the stage of pregnancy, the radiation dose, and the amount of the treatment area covering the foetus. The Interna- tional Commission on Radiological Protection (ICRP) considers doses lower than $1 \mathrm{mGy}$ to have negligible effect on the foetus and doses of a few mGy are permitted and are not associated with an increased risk of birth defects [13]. Frequent side effects associated with the use of radiation therapy (RT) during pregnancy are fatal damage, miscarriage, organ damage, stunted physical and mental health of the foetus, and carcinogenesis [14]. Exposure of the foetus to radiation doses exceeding 5-10 cGy should be avoided. Doses below this limit are associated with a very low risk of mutation, and developmental disorders do not occur at a frequency higher than that observed in the general population (3-5\%). Exposure to anticancer agents should be avoided in the first trimester (organogenesis), but can be justified, at the cost of a slight increase in the risk for mother and foetus, in the second and third trimesters of pregnancy $[15,16]$. Table 2 shows the summary of potential effects on the developing embryo/foetus.

\section{Treatment of tumours occurring during pregnancy}

\section{Breast cancer}

Pregnancy-associated breast cancer (PABC) is defined as breast cancer occurring at any time during pregnancy, lactation, or within one year after the delivery. It occurs at a frequency of 1/3000-1/10,000 pregnancies, and about $3 \%$ of all breast cancers coexist with pregnancy [17]. Physiological changes in the mammary gland during pregnancy contribute to the delay in the diagnosis of breast cancer in pregnant women, amounting to an average of 5-7 months. The probability of detection of a metastatic tumour during pregnancy is 2.5 times higher than in the general population, and the presence of metastases in regional lymph nodes is revealed in as many as $60 \%$ of cases [14, 17]. During pregnancy, usually unfavourable, poorly differentiated forms of breast tumour are diagnosed, and most of them (approximately 80\%) are characterised by the absence of expression of steroid receptors. Compared with

Table 2. Summary of potential effects on the developing embryo/ foetus ściągnięta z panelu, bez korekty

\begin{tabular}{|c|c|}
\hline $\begin{array}{l}\text { Stage of } \\
\text { pregnancy }\end{array}$ & Potential effects \\
\hline Preimplantation & $\begin{array}{l}\text { lethal effects, data from rodents indicate } \\
1.5 \% \text { loss with } 0.1 \mathrm{~Gy}, 50 \% \text { loss with } 1 \mathrm{~Gy}\end{array}$ \\
\hline $\begin{array}{l}\text { Postimplantation } \\
\text { weeks } 1 \text { to } 8\end{array}$ & $\begin{array}{l}\text { mental retardation, multiorgan } \\
\text { malformation, growth retardation, } \\
\text { microcephaly }\end{array}$ \\
\hline weeks 8 to 15 & $\begin{array}{l}\text { mental retardation, microcephaly, possible } \\
\text { skeletal and genital abnormalities, growth, } \\
\text { retardation }\end{array}$ \\
\hline weeks 15 to 25 & $\begin{array}{l}\text { major malformations unlikely, mild } \\
\text { microcephaly, mental retardation, growth } \\
\text { retardation }\end{array}$ \\
\hline weeks > 30 & $\begin{array}{l}\text { unlikely to produce structural } \\
\text { abnormalities, growth retardation still } \\
\text { possible, major risks are increased cancer } \\
\text { risk and potential effect on fertility }\end{array}$ \\
\hline
\end{tabular}


Table 1. The main risks to the foetus of chemotherapeutic agents

\begin{tabular}{|c|c|}
\hline Examples of chemotherapeutic agents & The main risks to the foetus \\
\hline $\begin{array}{l}\text { Plant alkaloids: } \\
\text { vincristine, vinblastine, vinorelbine }\end{array}$ & $\begin{array}{l}\text { Preterm delivery, intrauterine growth restriction (IUGR) [67]. Defect } \\
\text { in the atrial septum [68]. }\end{array}$ \\
\hline $\begin{array}{l}\text { Anthracycline antibiotics: } \\
\text { doxorubicin, daunorubicin, adriamycin, idarubicin, epirubicin, } \\
\text { dactinomycine, bleomycin, mitoxantrone }\end{array}$ & $\begin{array}{l}\text { Mid-trimester miscarriage, transient neonatal neutropenia, and } \\
\text { sepsis, IUGR [69]. Transient myelosuppression [70]. }\end{array}$ \\
\hline $\begin{array}{l}\text { Alkylating agents: } \\
\text { cyclophosphamide, busulfan, ifosphamide, chlorambucil, } \\
\text { carmustine, dacarbazine }\end{array}$ & $\begin{array}{l}\text { Absent toes, eye abnormalities, low-set ears, and cleft palate [71]. } \\
\text { Oesophageal atresia, abnormal inferior vena cava [72]. Pyloric } \\
\text { stenosis, renal agenesis, and liver calcifications [73]. }\end{array}$ \\
\hline $\begin{array}{l}\text { Antimetabolites: } \\
\text { Methotrexate, } 5 \text {-fluorouracil, aminopterin, cytarabine, } \\
\text { mercaptopurine. }\end{array}$ & $\begin{array}{l}\text { Spontaneous abortions }[68,74] \text {. Ventriculomegaly, microcephaly, } \\
\text { syndactyly, deficient growth and development [75-77]. }\end{array}$ \\
\hline Cisplatin and carboplatin & Sensorineural hearing loss, respiratory distress syndrome $[10,78]$. \\
\hline Trastuzumab & $\begin{array}{l}\text { Kidney injury [79] kidney perfusion [80]. Respiratory failure, } \\
\text { capillary fragility, and neonatal death [33]. }\end{array}$ \\
\hline
\end{tabular}

the cases occurring independently of pregnancy, tumours occurring during pregnancy often overexpress HER2 [18].

The available data indicate that surgery is safe throughout pregnancy. Surgery is the primary treatment for early breast cancer. Modified radical mastectomy is the standard treatment in the first trimester of pregnancy. However, as a result of the required delay with the adjuvant radiation therapy, due to the risk to the foetus, a modified mastectomy is often performed. Following breast-conserving surgery, a complementary RT is administered after 3-6 weeks. In case a systemic treatment is needed, RT begins 3-6 weeks after CHTH. Therefore, a sparing surgery (with dissection) is preferably carried out in the second and third trimester of pregnancy $[19,20]$. In these cases, radiation therapy is performed after birth. The lowest risk of miscarriage occurs in women treated surgically after 12 weeks of pregnancy [11, 21].

There are currently no adequate data on the safety of sentinel lymph node biopsy (SLNB) in pregnancy. In a prospective study $[22,23]$ involving 12 pregnant patients with breast cancer who underwent the removal of lymph nodes with a radioactive marker, 11 children were born healthy and one was diagnosed with a hole in the septum of the heart. There is also the risk of an anaphylactic reaction in the mother in connection with the SLNB procedure [24]. The technique used to perform sentinel lymph node mapping was also evaluated in multiple studies, and the accuracy rate increases when radiocolloid and blue dye are used in combination [25].

To summarise, SLNB can be performed in selected cases and only at oncology centres employing staff with appropriate experience [25]. Radiation therapy in the first trimester of pregnancy can cause developmental defects, microcephaly, mental retardation, growth retardation, haematological disorders, and can induce childhood cancer [26, 27].

An alternative to external beam radiotherapy appears to be an electron beam intraoperative radiotherapy (ELIOT) after a surgical, breast-conserving treatment. During the first and second trimester of pregnancy, ELIOT may be considered as part of the breast-conserving approach.
After 30 weeks of pregnancy, when the foetus is much closer to the breast than at earlier stages, ELIOT is less secure [28].

Chemotherapy should be indicated for use in patients with unfavourable prognosis and should be completed in the second and third trimesters of pregnancy (e.g. 4-6 cycles of AC or FAC regimens: doxorubicin and cyclophosphamide or doxorubicin, cyclophosphamide, and fluorouracil). The risk for the foetus related with FAC chemotherapy as adjuvant therapy is small $[29,30]$. Hormone therapy is not used in pregnant patients because of the risk of its interference with the hormonal status associated with pregnancy, and additionally because of the high teratogenic potential of tamoxifen [31].

In women with locally advanced or metastatic breast cancer with overexpression of HER2, after failure of at least one chemotherapy, lapatinib (a small-molecule tyrosine kinase inhibitor of EGFR) can be used. To date, one case of pregnancy during treatment with lapatinib, used up to 14 weeks of gestation, has been described. During the 18-month follow-up period after birth, no defects in the child were revealed [30].

According to ESMO (European Society for Medical Oncology) and the NCCN (National Comprehensive Cancer Network) Clinical Practice Guidelines in Oncology, the use of trastuzumab is contraindicated in pregnancy. In the literature on the use of trastuzumab in pregnant women, few cases have been described. Treatment with trastuzumab is associated with oligohydramnios (sometimes severe), lung aplasia, dysplastic kidney, and death shortly after birth [31-33]. Although the termination of pregnancy facilitates the therapy, it does not improve the prognosis $[9,16,21,26]$. No data on breast reconstructive surgery in pregnancy are available.

\section{Cervical cancer}

Cervical cancer is the most frequent gynaecological tumour diagnosed in pregnant women. As many as $1 \%$ of women diagnosed with cervical cancer are pregnant. The role of pregnancy in the carcinogenesis of cervical can- 
cer, as well as in the treatment and prognosis, is still under discussion [34]. There are no reports suggesting that pregnancy worsens the prognosis. The survival rates of pregnant and non-pregnant women with invasive cervical cancer are similar [35]. Treatment during pregnancy can be selected based on the following circumstances: intention to maintain the pregnancy, gestational age, and cancer stage. During pregnancy, surgical interventions in the pelvic area are seriously complicated. Therefore, it is very difficult to perform a resection with optimal scope from an oncological perspective [36].

In the case of cervical cancer diagnosed after the $20^{\text {th }}$ week of pregnancy, the treatment can be postponed until foetal maturity. The delivery may be by Caesarean section. There are no controlled, randomised studies of the impact of this delay on the results of cancer treatment. However, possible threats related with cancer treatment should be discussed with the patient. If a woman diagnosed with cervical cancer in the first trimester of pregnancy wishes to maintain the pregnancy, conservative treatment until the second trimester is recommended.

Conisation is a treatment of choice at stage IA [37]. Conisation and radical trachelectomy are performed if the woman intends to maintain the pregnancy. During pregnancy, the risk of bleeding increases. To reduce the risk of blood loss and abortion, the most favourable time for cervical conisation is in the second trimester, between weeks 14 and 20 [37]. Radical trachelectomy during pregnancy poses great risk and may result in massive bleeding and pregnancy loss [38].

Radiation therapy (RT) should not be considered during pregnancy if the mother intends to maintain it [39]. In the first trimester of pregnancy, RT results in abortion. In the second trimester of pregnancy, foetal death occurs after 10-15 fractions of RT [14].

In pregnant women with cervical cancer at stage IA2IB1, lymph node biopsy should be performed first. In the case of a negative verification of nodal metastases, treatment can start with neoadjuvant chemotherapy followed by trachelectomy. Neoadjuvant chemotherapy may be used after the completion of organogenesis (pregnancy week 13) [40, 41]. At stage IB2-IIB, neoadjuvant chemotherapy is offered once foetal maturity is achieved.

Standard treatment (radical hysterectomy or radiochemotherapy) is used when lymph nodes are positive. Standard treatment is considered if there is poor response to induction chemotherapy. At more advanced stages (IIA2IIIB), classical therapy (radical hysterectomy or radiochemotherapy) should be used when appropriate gestational age is reached.

In conclusion, spontaneous abortion occurred in all patients treated with radiation therapy. However, in patients treated with cisplatin alone administered once a week, the course of pregnancy was normal [39]. In the case of cervical cancer diagnosed in the first trimester of pregnancy, the treatment should be postponed to the second trimester. Treatment used in patients with cervical cancer diagnosed in the second trimester of pregnancy depends on tumour stage. Cervical cancer diagnosed in the third tri- mester is an indication for Caesarean section due to foetal maturity, followed by standard therapy [42].

\section{Lymphomas}

Hodgkin's lymphoma is the most common haematological malignancy reported during pregnancy. The incidence is estimated at 0.01 per 1,000 pregnancies. Currently, the standard treatment is chemotherapy alone $(\mathrm{CTH})$ or in combination with radiation therapy (RT-CTH) [43]. Either the area of the irradiated field or the dose of radiation (20-30 Gy) is smaller. Treatment using CTH in the second and third trimester of pregnancy is considered relatively safe. However, in the case of patients who underwent $\mathrm{CTH}$ in the first trimester, an increased incidence $(6 / 17)$ of developmental birth defects has been noted. Therefore, in women diagnosed with Hodgkin's disease during pregnancy, the regimen ABVD (doxorubicin, bleomycin, vinblastine, dacarbazine) may be considered at standard doses starting from the $2^{\text {nd }}$ trimester [44].

In most cases in which radiation therapy is desired, it may be delayed until the birth of the child. In situations when radiation therapy is necessary during pregnancy, several case reports have been published that have demonstrated the ability to deliver therapeutic doses of radiation with very low doses to the developing foetus [16]. When modern techniques of radiation therapy are used, a reduction in both the irradiated volume and the dose absorbed by the foetus may be achieved.

A few-week delay in the consolidation radiation therapy may not affect overall survival, and, as in the case of all previously discussed decisions, the conversation between the patient and the oncologist is important in making therapeutic decisions.

\section{Melanoma}

The incidence of melanoma in pregnant women is estimated at 0.14-2.8 per 1,000. Melanoma accounts for approximately $8 \%$ of all cancers coexisting with pregnancy [45]. The effect of pregnancy on melanoma is not clearly established. In patients with melanoma occurring during pregnancy, the postpartum placenta must be evaluated in order to detect pathological lesions or exclude metastases. The confirmation of the presence of metastases requires close observation of children for the development of cancer [46]. Primary treatment is based on a surgery involving excision with a margin of $2.5-5 \mathrm{~cm}$ (depending on the depth of lesion). At stages I and II, excision of the sentinel lymph node can be considered. At stages III and IV, lymph nodes along with the possible satellite nodules should be cut. Immunotherapy with interferon in pregnant women with metastatic melanoma appears to be safe [46, 47]. Adjuvant radiation therapy in pregnancy is limited to the lesions of the head and neck, brain metastases, and palliative treatment of recurrent or metastatic disease at sites other than the central nervous system. Metastases in the brain (if limited) are often treated with radiosurgery or neurosurgical resection. Delaying the treatment of metastatic lesions in the brain is not advisable. Radiosurgery delivers very high doses to very small volumes in the brain 
and, with careful treatment planning, it should be possible to treat a pregnant patient with a minimal exposure to the foetus [48]. Chemotherapy is of no practical use in such cases [49].

\section{Thyroid cancer}

Thyroid cancer has a reported incidence of 14 cases per 100,000 pregnant women [50]. For all patients with tumour nodules or nodules that grow quickly, a surgery should be offered in the second trimester of pregnancy. Patients with early-stage follicular and papillary thyroid cancer are candidates for delaying the surgery because the lesions generally grow slowly [51]. No cases of accelerated locoregional recurrence or decreased survival have been reported in pregnant patients with thyroid cancer, as compared with non-pregnant patients [52].

\section{Ovarian cancer}

Ovarian cancer in pregnancy is rare and has occurred in 1 in 15,000 to 1 in 32,000 pregnancies. During pregnancy, malignant and borderline ovarian cancers account for $3 \%$ to $6 \%$ of cases. Ovarian pathologic types include epithelial (49-75\%), germ-cell (6-40\%), and sex cord stromal tumours (9-16\%) [53]. Because tumour markers during pregnancy are not helpful, the diagnostic methods mainly depend on ultrasonographic findings. Surgical interventions conducted too early may increase the risk of loss of luteal function and abortion. Therefore, it is recommended to conduct such interventions in the second trimester [53].

As germ cell tumours are sensitive to chemotherapy, fertility-sparing surgery (cytoreduction) is also recommended at advanced stages of the disease, even if the other ovary is intact. However, in the case of ovarian cancer, cytoreductive surgery should only be considered at stage IA/IB [53]. Advanced stages of ovarian cancer can be treated using various methods, including basic cytoreductive surgery followed by parturition, surgery during pregnancy followed by adjuvant chemotherapy after parturition, reductive surgery followed by chemotherapy during pregnancy and after parturition, and surgery during pregnancy followed by suspension of treatment [54-56].

Maintaining the pregnancy is very difficult if cancer has been diagnosed before the $20^{\text {th }}$ week. After 20 weeks of pregnancy, maintaining the pregnancy is possible but uncertain. Similarly as in non-pregnant women, the treatment of choice for preoperative chemotherapy is carboplatin + paclitaxel until foetal maturity $[57,58]$.

\section{Colorectal cancer}

Colorectal cancer in pregnancy is rare, and has occurred in 1 in 13,000 pregnancies [59]. The treatment and the prognosis in pregnant patients with colorectal cancer do not differ from those in the general population. There are several factors to be considered when planning the treatment: tumour location, gestational age, stage of the tumour, complications due to the tumour or due to the pregnancy, and the patient's decision. Unfortunately, colorectal cancer is often diagnosed during pregnancy at an advanced stage, when surgical treatment and complementary chemotherapy demonstrate poor efficacy [60]. Surgery may be conducted safely before the $20^{\text {th }}$ week of pregnancy [61]. It has been proposed that colorectal cancer surgery be conducted immediately after uncomplicated Caesarean section [60, 62].

Chemotherapy employing 5-fluorouracil (5-FU) used as standard treatment at stage III of colorectal cancer causes a high risk of teratogenic effect [60]. The most serious complications in chemotherapy occur between week 3 and week 12 of foetal life. In several case reports, chemotherapy using 5-FU in the first trimester of pregnancy resulted in spontaneous abortion $[63,64]$.

Cisplatin and its derivative chemotherapeutics are also used in the treatment of colorectal cancer, but they are not recommended during breastfeeding or pregnancy. Chemotherapy is safer in the second and third trimester of pregnancy, although an increase in the occurrence of intrauterine growth retardation and premature delivery has been observed [26].

\section{Supportive treatment}

Antiemetics (ondansetron, metoclopramide) may be safely used with cover corticosteroids during the first trimester of pregnancy [65]. The use of tropisetron is discouraged: studies have shown teratogenic effects in animals. Granisetron and palonosetron are rarely used in pregnancy. Analgesics (paracetamol, opioids, anti-inflammatory agents) were administered to pregnant women and, with the exception of the first trimester, did not generate adverse effects, but there is some risk of respiratory depression and foetal ductus arteriosus closure [66]. Bisphosphonates and somatostatin should be postponed until after the delivery due to their teratogenic effect observed in animals and humans. Treatment with anti-infective agents should follow the guidelines to avoid the teratogenic effects of these drugs.

The decision on the introduction and continuation of treatment in the event of pregnancy should be preceded by a detailed analysis of the potential benefits and risks. There are no data to suggest that pregnancy termination alters the biological behaviour of the tumour or patient prognosis in the presence of appropriate antineoplastic therapy. All patients should be given appropriate advice and informed that there are insufficient scientific data to determine any generally accepted consensus. It is very important to always respect the will of the patient, and the moral judgment of a physician should have no impact on the decisions taken by the woman. If the woman decides to undergo active treatment and maintain her pregnancy, it is necessary to carry out consultations with experts in the field appropriate to the type of cancer.

The authors declare no conflict of interest. 


\section{References}

1. Stovall M, Blackwell CR, Cundiff J, Novack DH, Palta JR, Wagner LK, Webster EW, Shalek RJ. Fetal dose from radiotherapy with photon beams: report of AAPM Radiation Therapy Committee Task Group. Med Phys 1995; 36: 63-82.

2. Eheman C, Henley SJ, Ballard-Barbash R, et al. Annual Report to the Nation on the status of cancer, 1975-2008, featuring cancers associated with excess weight and lack of sufficient physical activity. Cancer 2012; 118: 2338-66.

3. Ní Mhuireachtaigh R, O'Gorman DA. Anesthesia in pregnant patients for nonobstetric surgery. J Clin Anesth 2006; 18: 60-6.

4. Moran BJ, Yano H, Al Zahir N, Farquharson M. Conflicting priorities in surgical intervention for cancer in pregnancy. Lancet Oncol 2007; 8: 536-44.

5. Yuen PM, Ng PS, Leung PL, Rogers MS. Outcome in laparoscopic management of persistent adnexal mass during the second trimester of pregnancy. Surg Endosc 2004; 18: 1354-7.

6. Mathevet P, Nessah K, Dargent D, Mellier G. Laparoscopic management of adnexal masses in pregnancy: a case series. Eur J Obstet Gynecol Reprod Biol 2003; 108: 217-22.

7. Cohen-Kerem R, Railton C, Oren D, Lishner M, Koren G. Pregnancy outcome following non-obstetric surgical intervention. Am J Surg 2005; 190: 467-73.

8. Duncan PG, Pope WD, Cohen MM, Greer N. Fetal risk of anesthesia and surgery during pregnancy. Anesthesiology 1986; 64: 790-4.

9. Lawrenz B, Henes M, Neunhoeffer E, Fehm T, Huebner S, Kanz L, Marini P, Mayer F. Pregnancy after successful cancer treatment: what needs to be considered. Onkologie 2012; 35: 128-32.

10. Cardonick E, lacobucci A. Use of chemotherapy during human pregnancy. Lancet Oncol 2004; 35: 283-91.

11. Amant F, Loibl S, Neven P, Van Calsteren K. Breast cancer in pregnancy. Lancet 2012; 379: 570-9.

12. Gustavson KH, Jagell S, Blomquist HK, Nordenson I. Microcephaly, mental retardation and chromosomal aberrations in a girl following radiation therapy during late fetal life. Acta Radiol Oncol 1981; 20: 209-12

13. International Commission on Radiological Protection. Biological effects after prenatal irradiation (embryo, foetus). Annals of the ICRP 2003; 33: 205-6.

14. Kal HB, Struikmans $\mathrm{H}$. Use of radiotherapy during pregnancy: fact and fiction. Lancet Oncol 2005; 6: 328-33.

15. Pentheroudakis G, Orecchia R, Hoekstra HJ, Pavlidis N; ESMO Guidelines Working Group. Cancer, fertility and pregnancy: ESMO Clinical Practice Guidelines for diagnosis, treatment and follow-up. Ann Oncol 2010; 21: 266-73.

16. Martin DD. Review of radiation therapy in the pregnant cancer patient. Clin Obstet Gynecol 2011; 54: 591-601.

17. Litton JK, Theriault RL. Breast cancer and pregnancy: current concepts in diagnosis and treatment. Oncologist 2010; 15: 1238-47.

18. Elledge RM, Ciocca DR, Langone G, McGuire WL. Estrogen receptor, progesterone receptor, and HER2/neu protein in breast cancer from pregnant patients. Cancer 1993; 71: 2499-506.

19. Middleton LP, Amin M, Gwyn K, et al. Breast carcinoma in pregnant women: assessment of clinicopathologic and immunohistochemical features. Cancer 2003; 98: 1055-60.

20. Pirvulescu C, Mau C, Schultz H, et al. Breast cancer during pregnancy: an interdisciplinary approach in our institution. Breast Care (Basel) 2012; 7: 311-4.

21. Vinatier E, Merlot B, Poncelet E, Collinet P, Vinatier D. Breast cancer during pregnancy. Eur J Obstet Gynecol Reprod Biol 2009; 147: 9-14.

22. Gentilini O, Cremonesi M, Trifir G, et al. Safety of sentinel node biopsy in pregnant patients with breast cancer. Ann Oncol 2004; 15: $1348-51$.

23. Gentilini O, Cremonesi M, Toesca A, et al. Sentinel lymph node biopsy in pregnant patients with breast cancer. Eur J Nucl Med Mol Imaging 2010; 37: 78-83.

24. Khera SY, Kiluk JV, Hasson DM, Meade TL, Meyers MP, Dupont EL, Berman CG, Cox CE. Pregnancy-associated breast cancer patients can safely undergo lymphatic mapping. Breast J 2008; 14: 250-4.

25. Wiatrek R, Kruper L. Sentinel lymph node biopsy indications and controversies in breast cancer. Maturitas 2011; 69: 7-10.
26. Amant F, Deckers S, Van Calsteren K, et al. Breast cancer in pregnancy: recommendations of an international consensus meeting. Eur J Cancer 2010; 46: 3158-68.

27. Azim HA Jr, Del Mastro L, Scarfone G, Peccatori FA. Treatment of breast cancer during pregnancy: regimen selection, pregnancy monitoring and more. Breast 2011; 20: 1-6.

28. Galimberti V, Ciocca M, Leonardi MC, et al. Is electron beam intraoperative radiotherapy (ELIOT) safe in pregnant women with early breast cancer? In vivo dosimetry to assess fetal dose. Ann Surg Oncol 2009; 16: 100-5.

29. Martin DD. Review of radiation therapy in the pregnant cancer patient. Clin Obstet Gynecol 2011; 54: 591-601.

30. Kelly H, Graham M, Humes E, et al. Delivery of a healthy baby after first-trimester maternal exposure to lapatinib. Clin Breast Cancer 2006; 7: 339-41.

31. Azim HA Jr, Kroman N, Paesmans M, et al. Prognostic impact of pregnancy after breast cancer according to estrogen receptor status: a multicenter retrospective study. J Clin Oncol 2013; 31: 73-9.

32. Beale JM, Tuohy J, McDowell SJ. Herceptin (trastuzumab) therapy in a twin pregnancy with associated oligohydramnios. Am J Obstet Gynecol 2009; 201: 13-14.

33. Witzel ID, Müller V, Harps E, Janicke F, Dewit M. Trastuzumab in pregnancy associated with poor fetal outcome. Ann Oncol 2008; 19: 191-2.

34. Morice P, Uzan C, Gouy S, Verschraegen C, Haie-Meder C. Gynaecological cancers in pregnancy. Lancet 2012; 379: 558-69.

35. Pavlidis NA. Coexistence of pregnancy and malignancy. Oncologist 2002; $7:$ : 279-87.

36. Amant F, Brepoels L, Halaska MJ, Gziri MM, Calsteren KV. Gynaecologic cancer complicating pregnancy: an overview. Best Pract Res Clin Obstet Gynaecol 2010; 24: 61-79.

37. Van Calsteren K, Vergote I, Amant F. Cervical neoplasia during pregnancy: diagnosis, management and prognosis. Best Pract Res Clin Obstet Gynaecol 2005; 19: 611-30.

38. Ungár L, Smith JR, Pálfalvi L, Del Priore G. Abdominal radical trachelectomy during pregnancy to preserve pregnancy and fertility. Obstet Gynecol 2006; 108: 811-4.

39. Azim HA Jr, Peccatori FA, Pavlidis N. Treatment of the pregnant mother with cancer: a systematic review on the use of cytotoxic, endocrine, targeted agents and immunotherapy during pregnancy Part I: Solid tumors. Cancer Treat Rev 2010; 36: 101-9.

40. Caluwaerts S, VAN Calsteren K, Mertens L, et al. Neoadjuvant chemotherapy followed by radical hysterectomy for invasive cervical cancer diag- nosed during pregnancy: report of a case and review of the literature. Int J Gynecol Cancer 2006; 16: 905-8.

41. Karam A, Feldman N, Holschneider CH. Neoadjuvant cisplatin and radical cesarean hysterectomy for cervical cancer in pregnancy. Nat Clin Pract Oncol 2007; 4: 375-80.

42. Ji YI, Kim KT. Gynecologic malignancy in pregnancy. Obstet Gynecol Sci 2013; 56: 289-300.

43. Brenner B, Avivi I, Lishner M. Haematological cancers in pregnancy. Lancet 2012; 379: 580-7.

44. Cohen JB, Blum KA. Evaluation and management of lymphoma and leukemia in pregnancy. Clin Obstet Gynecol 2011; 54: 556-66.

45. Jhaveri MB, Driscoll MS, Grant-Kels JM. Melanoma in pregnancy. Clin Obstet Gynecol 2011; 54: 537-45.

46. Alexander A, Samlowski WE, Grossman D, et al. Metastatic melanoma in pregnancy: risk of transplacental metastases in the infant. J Clin Oncol 2003; 21: 2179-86.

47. Hauschild A, Gogas H, Tarhini A, Middleton MR, Testori A, Dréno $B$, Kirkwood JM. Practical guidelines for the management of interferon-alpha-2b side effects in patients receiving adjuvant treatment for melanoma: expert opinion. Cancer 2008; 112: 982-94.

48. Izycki D, Kerrigan CP, Kazmierczak M. Melanoma in pregnancy - where we are? Menopause Review 2013; 6: 493-5.

49. Pavlidis N. Cancer and pregnancy: what should we know about the management with systemic treatment of pregnant women with cancer. Eur J Cancer 2011; 47: 348-52.

50. Smith LH, Danielsen B, Allen ME, Cress R. Cancer associated with obstetric delivery: results of linkage with the California cancer registry. Am J Obstet Gynecol 2003; 189: 1128-35.

51. Voulgaris E, Pentheroudakis G, Pavlidis N. Cancer and pregnancy: a comprehensive review. Surg Oncol 2011; 20: 175-85. 
52. Moosa M, Mazzaferri EL. Outcome of differentiated thyroid cancer diagnosed in pregnant women. J Clin Endocrinol Metab 1997; 82: 2862-6.

53. Giuntoli RL 2nd, Vang RS, Bristow RE. Evaluation and manage ment of adnexal masses during pregnancy. Clin Obstet Gynecol 2006; 49: 492-505.

54. Tabata T, Nishiura K, Tanida K, Kondo E, Okugawa T, Sagawa N. Carboplatin chemotherapy in a pregnant patient with undifferentiated ovarian carcinoma: case report and review of the literature. Int J Gynecol Cancer 2008; 18: 181-4.

55. Modares Gilani M, Karimi Zarchi M, Behtash N, Ghaemmaghami F, Mousavi AS, Behnamfar F. Preservation of pregnancy in a patient with advanced ovarian cancer at 20 weeks of gestation: case report and literature review. Int J Gynecol Cancer 2007; 17: 1140-3.

56. Méndez LE, Mueller A, Salom E, González-Quintero VH. Paclitaxe and carboplatin chemotherapy administered during pregnancy for advanced epithelial ovarian cancer. Obstet Gynecol 2003; 102: 1200-2.

57. Picone O, Lhommé C, Tournaire M, Pautier P, Camatte S, Vacher-Lavenue MC, Castaigne D, Morice P. Preservation of pregnancy in a patient with a stage IIIB ovarian epithelial carcinoma diagnosed at 22 weeks of gestation and treated with initial chemotherapy: case report and literature review. Gynecol Oncol 2004; 94: 600-4.

58. Machado F, Vegas C, Leon J, Perez A, Sanchez R, Parrilla JJ, Abad L. Ovarian cancer during pregnancy: analysis of 15 cases. Gynecol Oncol 2007; 105: 446-50.

59. Woods JB, Martin JN Jr, Ingram FH, Odom CD, Scott-Conner CE, Rhodes RS. Pregnancy complicated by carcinoma of the colon above the rectum. Am J Perinatol 1992; 9: 102-10.

60. Walsh C, Fazio VW. Cancer of the colon, rectum, and anus during pregnancy. The surgeon's perspective. Gastroenterol Clin North Am 1998; 27: 257-67.

61. Cohen-Kerem R, Railton C, Oren D, Lishner M, Koren G. Pregnancy outcome following non-obstetric surgical intervention. Am J Surg 2005; 190: 467-73.

62. Schirmer B, Kouretas PC. Gallstone pancreatitis. In: Cameron JL (ed.). Current surgical therapy. 7th ed. Mosby, Philadelphia, PA 2001; 528-33.

63. Dreicer R, Love RR. High total dose 5-fluorouracil treatment during pregnancy. Wis Med J 1991; 90: 582-3.

64. Ring AE, Smith IE, Jones A, Shannon C, Galani E, Ellis PA. Chemotherapy for breast cancer during pregnancy: an 18-year experience from five London teaching hospitals. J Clin Oncol 2005; 23: 4192-7.

65. Mazzotta P, Magee LA. A risk-benefit assessment of pharmacological and nonpharmacological treatments for nausea and vomiting of pregnancy. Drugs 2000; 59: 781-800.

66. Jackson E, Kapp N. Pain control in first-trimester and second-trimester medical termination of pregnancy: a systematic review. Contraception 2011; 83: 116-26.

67. Peres RM, Sanseverino MT, Guimar es JL, Coser V, Giuliani L, Moreira RK, Ornsten T, Schüler-Faccini L. Assessment of fetal risk associated with exposure to cancer chemotherapy during pregnancy: a multicenter study. Braz J Med Biol Res 2001; 34: 1551-9.

68. Ebert U, Löffler H, Kirch W. Cytotoxic therapy and pregnancy. Pharmacol Ther 1997; 74: 207-20.

69. Karp GI, von Oeyen P, Valone F, Khetarpal VK, Israel M, Mayer RJ, Frigoletto FD, Garnick MB. Doxorubicin in pregnancy: possible transplacental passage. Cancer Treat Rep 1983; 67: 773-7.

70. Loibl S, Han SN, von Minckwitz G, et al. Treatment of breast cancer during pregnancy: an observational study. Lancet Oncol 2012; 13: 887-96

71. Doll DC, Ringenberg QS, Yarbro JW. Antineoplastic agents and pregnancy. Semin Oncol 1989; 16: 337-45.

72. Wagner VM, Hill JS, Weaver D, Baehner RL. Congenital abnormalities in baby born to cytarabine-treated mother. Lancet 1980; 2: 98-9.

73. Boros SJ, Reynolds JW. Intrauterine growth retardation following third-trimester exposure to busulfan. Am J Obstet Gynecol 1977; 129: $111-2$
74. Warkany J, Beaudry PH, Hornstein S. Attempted abortion with aminopterin. AMA J Dis Child 1959; 97: 274-81.

75. Paskulin GA, Gazzola Zen PR, de Camargo Pinto LL, Rosa R, Graziadio C. Combined chemotherapy and teratogenicity. Birth Defects Res A Clin Mol Teratol 2005; 73: 634-7.

76. Hahn KM1, Johnson PH, Gordon N, et al. Treatment of pregnant breast cancer patients and outcomes of children exposed to chemotherapy in utero. Cancer 2006; 107: 1219-26.

77. Leyder M, Laubach M, Breugelmans M, Keymolen K, De Greve J, Foulon W. Specific congenital malformations after exposure to cyclophosphamide, epirubicin and 5-fluorouracil during the first trimester of pregnancy. Gynecol Obstet Invest 2011; 71: 141-4.

78. Avilés A, Neri N. Hematological malignancies and pregnancy: a final report of 84 children who received chemotherapy in utero. Clin Lymphoma 2001; 2: 173-7.

79. Beale JM1, Tuohy J, McDowell SJ. Herceptin (trastuzumab) therapy in a twin pregnancy with associated oligohydramnios. Am J Obstet Gynecol 2009; 201: e13-e14.

80. Weber-Schoendorfer C, Schaefer C. Trastuzumab exposure during pregnancy. Reprod Toxicol 2008; 25: 390-1.

\section{Address for correspondence}

Krzysztof Roszkowski MD, PhD

Department of Radiotherapy

F. Lukaszczyk Oncology Centre

Romanowskiej 2, 85-796 Bydgoszcz, Poland

tel. +48 52 3743744; fax +48523743568

e-mail: roszkowskik@co.bydgoszcz.pl

Submitted: 27.07 .2014

Accepted: 8.08 .2014 